\title{
Molten Salt Synthesis of Water-Dispersible Polymeric Carbon \\ Nitride Nanoseaweeds and their Application as Luminescent
}

\section{Probes}

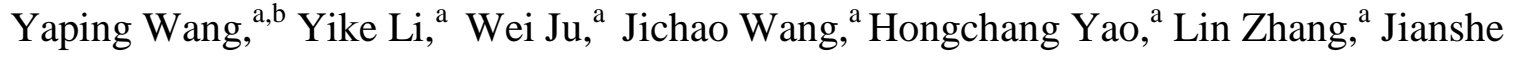

Wang ${ }^{\mathrm{a}}$ * and Zhongjun $\mathrm{Li}^{\mathrm{a}}{ }^{\mathrm{a}}$ *

${ }^{a}$ College of Chemistry and Molecular Engineering, Zhengzhou University, No.100 Science Avenue, Zhengzhou 450001, P. R. China

${ }^{\mathrm{b}}$ College of Chemistry and Chemical Engineering, Zhengzhou Normal University, No.6 yingcai

Road, Zhengzhou 450044, P. R. China

* Corresponding author. Tel: 86 0371-67783123. E-mail address: jianshewang @ zzu.edu.cn (J.S. Wang), lizhongjun@ zzu.edu.cn (Z.J. Li).

(C) 2016. This manuscript version is made available under the Elsevier user license

http://www.elsevier.com/open-access/userlicense/1.0/ 
ABSTRACT: A molten salt method has been developed for synthesis of polymeric carbon nitride nanoseaweeds (CNNSs) using melamine and $\mathrm{NaCl} / \mathrm{KCl}$ as precursor and eutectic salts, respectively. The resulting CNNSs present uniform shape which are about 20 nanometers wide and several hundred nanometers long. Moreover, they show excellent water dispersibility and enhanced photoluminescence properties, which make the CNNSs possess the potential as luminescent probes. Employed tetracycline (TC) as target, we have investigated the feasibility of utilizing the CNNSs for TC detection and the results demonstrate high selectivity and sensitivity, with detection limit of $0.04 \mu \mathrm{M}$. Interestingly, this work provides a general method to synthesize CNNSs from other precursors, such as guanidine hydrochloride and dicyandiamide.

\section{Introduction}

The last decades have witnessed the rapid development of luminescent probes which have extensive applications in biological field and chemosensing. Various luminescent probes, including semiconductor quantum dots [1], lanthanide-doped nanocrystals [2], silicon dots [3], carbon nanomaterials [4-6], metal nanoclusters [7], silica nanoparticles [8], and polymer nanoparticles $[9,10]$, have been developed so far. However, they always suffer from more or less disadvantages, such as inherent toxicity, photobleaching, lower quantum yield, poor water dispersibility or high cost [11]. Therefore, it is still a challenge to develop ideal nanomaterials for luminescent probes.

Carbon nitride can be easily prepared by the polycondensation of organic precursors, such as melamine, urea, cyanamide and dicyandiamide [12]. Due to suitable electronic band structure, carbon nitride has been widely used as photocatalyst for hydrogen evolution [13-17], the 
reduction of $\mathrm{CO}_{2}$ [18-22], the degradation of organic pollutants [23, 24], organic synthesis [25, 26] and oxygen reduction [27-29], electrochemical sensors [30, 31], electrode material for fuel cell of batteries [32]. Recently, in view of their biocompatibility, nontoxicity, inexpensive precursors and photoluminescence (PL) properties [33], carbon nitride owns new application as luminescent probes. Nevertheless, the macroscopic size and limited PL properties hinder its applications in biological field and chemosensing [34].

More recently, some efforts have been made to prepare water-dispersible luminescent carbon nitride nanosheets or nanodots. The strategies can be divided into two categories: ultrasonic exfoliation [34, 35] and chemical oxidation in strong acid or strong alkali aqueous solution [3638]. Sometimes, both of these strategies were used in combination [39, 40]. Although the ultrasonic exfoliation offers a simple method, its inherent drawbacks are the time-consuming ultrasonic and low yield. For chemical oxidation process, it is involving a great deal of strong acids or strong alkalis that is the main obstacle. Clearly, it is significant to explore convenient and environmentally-friendly methods for synthesizing water-dispersible nanosized carbon nitride with excellent PL properties.

Molten salt synthesis regarded as a green process, has been used for preparing a wide range of nanomaterials. What's more, the strategy can increase the crystallinity of materials and control the shape of nanostructure [41]. With the help of eutectic salts, such as $\mathrm{LiCl} / \mathrm{KCl}, \mathrm{LiBr} / \mathrm{KBr}$ and $\mathrm{LiCl} / \mathrm{ZnCl}_{2}, \mathrm{LiCl} / \mathrm{KCl} / \mathrm{NaCl}$, whose melting points are below the condensation temperature of melem $\mathrm{C}_{6} \mathrm{~N}_{7}\left(\mathrm{NH}_{2}\right)_{3}$, carbon nitride with high crystallinity and controllable shape have been achieved [42-49]. More recently, the polycondensation of dicyandiamide was carried out in $\mathrm{NaCl}$ crystals and carbon nitride ribbons were obtained. The results indicate that $\mathrm{NaCl}$ can play a role of templates to control the shape of carbon nitride [50]. 
The above mentioned carbon nitride are good candidates for visible light driving catalysts, but unfortunately they are not suitable for luminescent probes owing to large size, poor water dispersibility [51] and limited PL $[48,49,52]$. In the present work, the $\mathrm{NaCl} / \mathrm{KCl}$ eutectic mixture $\left(T_{\mathrm{m}}=658^{\circ} \mathrm{C}\right)$ and melamine were chosen as reaction medium and precursor, respectively. We not only achieve nanosized polymeric carbon nitride with special seaweed-like shape, but also dramatically improve their water dispersibility and PL properties. More important, further research indicates this strategy is a versatile method which can be applied to other precursors, such as guanidine hydrochloride and dicyandiamide.

\section{Experimental}

\subsection{Preparation of polymeric carbon nitride nanoseaweeds (CNNSs)}

CNNSs were prepared by condensation of melamine in molten salt system. In a typical process, $8 \mathrm{~g}$ melamine was used as precursor, and the eutectic mixture of $\mathrm{NaCl} / \mathrm{KCl}(1: 1$ molar ratio) with a melting point of $658{ }^{\circ} \mathrm{C}$ was used [41]. Melamine and the eutectic mixture of $\mathrm{NaCl} / \mathrm{KCl}$ with the mass ratio of 1:2.8 were prepared and ground to fine powders. Then the powders were placed into a crucible with a cover and heated at $670{ }^{\circ} \mathrm{C}$ for an hour in static air with a ramp rate of 10 ${ }^{\circ} \mathrm{C} \min ^{-1}$. The resulting yellow agglomerates were milled into powders, washed thoroughly with dilute hydrochloric acid several times and dispersed into deionized water. The final yield of CNNSs was calculated to be approximate $10 \%$.

\subsection{Preparation of bulk polymeric carbon nitride $(\mathrm{CN})$}

Bulk $\mathrm{CN}$ was prepared by polymerization of melamine molecules under high temperature. In detail, melamine was heated to $670{ }^{\circ} \mathrm{C}$ at $10{ }^{\circ} \mathrm{C} \min ^{-1}$ and kept for an hour. The resultant yellow material was milled into powder in a mortar for further investigation. 
Besides, a series of products were prepared by condensation of melamine in salt system at different temperature according to the same procedure. The as-obtained materials will be denoted as $\mathrm{CN}(\mathrm{x}-\mathrm{y})$, where $\mathrm{x}$ refers to the salts, $\mathrm{y}$ refers to the heating temperature.

\subsection{Characterizations}

UV-vis spectra were recorded on a Cary 5000 UV-vis spectrometer (Agilent Technologies, USA) by using $\mathrm{BaSO}_{4}$ as a reference. X-ray powder diffraction experiments were carried out with a X-ray diffractometer (PANalytical X' pert PRO, Netherlands) operating at $40 \mathrm{kV}$ and 40 $\mathrm{mA}$, using $\mathrm{Cu} \mathrm{Ká}$ radiation $(\lambda=1.540598 \AA) .{ }^{13} \mathrm{C}$ and ${ }^{15} \mathrm{~N}$ cross-polarization $(\mathrm{CP})$ magic-anglespinning (MAS) solid-state NMR spectra were recorded at ambient temperature on the conventional impulse spectrometer Avance II 300 (Bruker) operating at proton resonance frequencies of $75.5\left({ }^{13} \mathrm{C}\right)$ and $30.4 \mathrm{MHz}\left({ }^{15} \mathrm{~N}\right)$, respectively. The scanning electron microscopy observations were performed on JSM-7001F Thermal Field Emission SEM. The transmission electron microscopy images, STEM images and elemental mapping images were obtained by using a TECNAI G2 F20 microscope (FEI, USA) at $200 \mathrm{KV}$. FTIR spectra were recorded on a Nicolet Nexus 470 spectrometer on samples embedded in $\mathrm{KBr}$ pellets. The $\mathrm{pH}$ values of the aqueous solutions were determined with a shanghai REX PHSJ-3F pH meter (Shanghai, China). X-ray photoelectron spectroscopy (XPS) measurements were carried out in a Thermo escalab 250Xi instrument (Thermo, USA) with a $150 \mathrm{~W} \mathrm{Al} \mathrm{K \alpha}$ as the excitation source. Prior to the analysis, the samples were evacuated at high vacuum and then introduced into the analysis chamber. The binding energies obtained in the XPS spectral analysis were corrected for specimen charging by referencing $\mathrm{C} 1 \mathrm{~s}$ to $284.8 \mathrm{eV}$. All fluorescence measurements were performed on a Hitachi F-7000 fluorescence spectrophotometer (Tokyo, Japan) in $1 \mathrm{~cm} \times 1 \mathrm{~cm}$ quartz cells. 


\subsection{Fluorescence quantum yield measurements}

The fluorescence quantum yield of CNNSs was calculated using the following equation:

$$
\phi=\phi_{\mathrm{R}} \times \frac{I}{I_{\mathrm{R}}} \times \frac{A}{A_{\mathrm{R}}} \times \frac{\eta^{2}}{\eta_{\mathrm{R}}^{2}}
$$

where $\phi$ and $A$ are the quantum yield and integrated emission intensity, $\eta$ and $I$ are the refractive index and optical density, respectively. The subscript $\mathrm{R}$ refers to the reference fluorophore of known quantum yield. In the present work, quinine sulfate was used as a reference. The quinine sulfate (literature $\phi=0.54$ ) was dissolved in $0.1 \mathrm{M} \mathrm{H}_{2} \mathrm{SO}_{4}$ (refractive index of 1.33) and the CNNSs were dissolved in deionized water $(\eta=1.33)$. In order to minimize re-absorption effects, the absorbance of the reference and the sample were both kept below 0.05 at an excitation wavelength of $360 \mathrm{~nm}[36]$.

\subsection{Fluorescent sensing of TC}

The TC detection was performed at room temperature in PBS $(0.2 \mathrm{M}, \mathrm{pH}=7.4)$ buffer solution. In a typical run, $300 \mu \mathrm{L}$ of the CNNS solution was added to $500 \mu \mathrm{L}$ of PBS buffer, followed by the addition of a calculated amount of TC solution. Then, the solutions were diluted to $5 \mathrm{~mL}$ and mixed thoroughly. Afterward, the mixture was transferred into a $1 \mathrm{~cm}$ quartz cuvette and the fluorescence emission spectrum was measured with excitation at $374 \mathrm{~nm}$. To evaluate selectivity of the measurement method, a variety of metal ions $\left(\mathrm{Pb}^{2+}, \mathrm{Ca}^{2+}, \mathrm{Al}^{3+}, \mathrm{Mg}^{2+}, \mathrm{Zn}^{2+}, \mathrm{Na}^{+}, \mathrm{K}^{+}, \mathrm{Cd}^{2+}\right.$, $\mathrm{Fe}^{3+}, \mathrm{Fe}^{2+}$ and $\mathrm{Cd}^{2+}$ ), amino acids (Lys, Phe, Ser, Gly, Glu, Pro, Cys, Leu, Ala), glucose, sucrose and other antibiotics (lincomycin, streptomycin, gentamycin, azithromycin, erythromycin) were introduced into the CNNSs dispersion with the identical concentration of $80 \mu \mathrm{M}$, respectively. Their fluorescence spectra were recorded under the same conditions.

\section{Results and discussion}


3.1 Preparation and Characterization of CNNSs
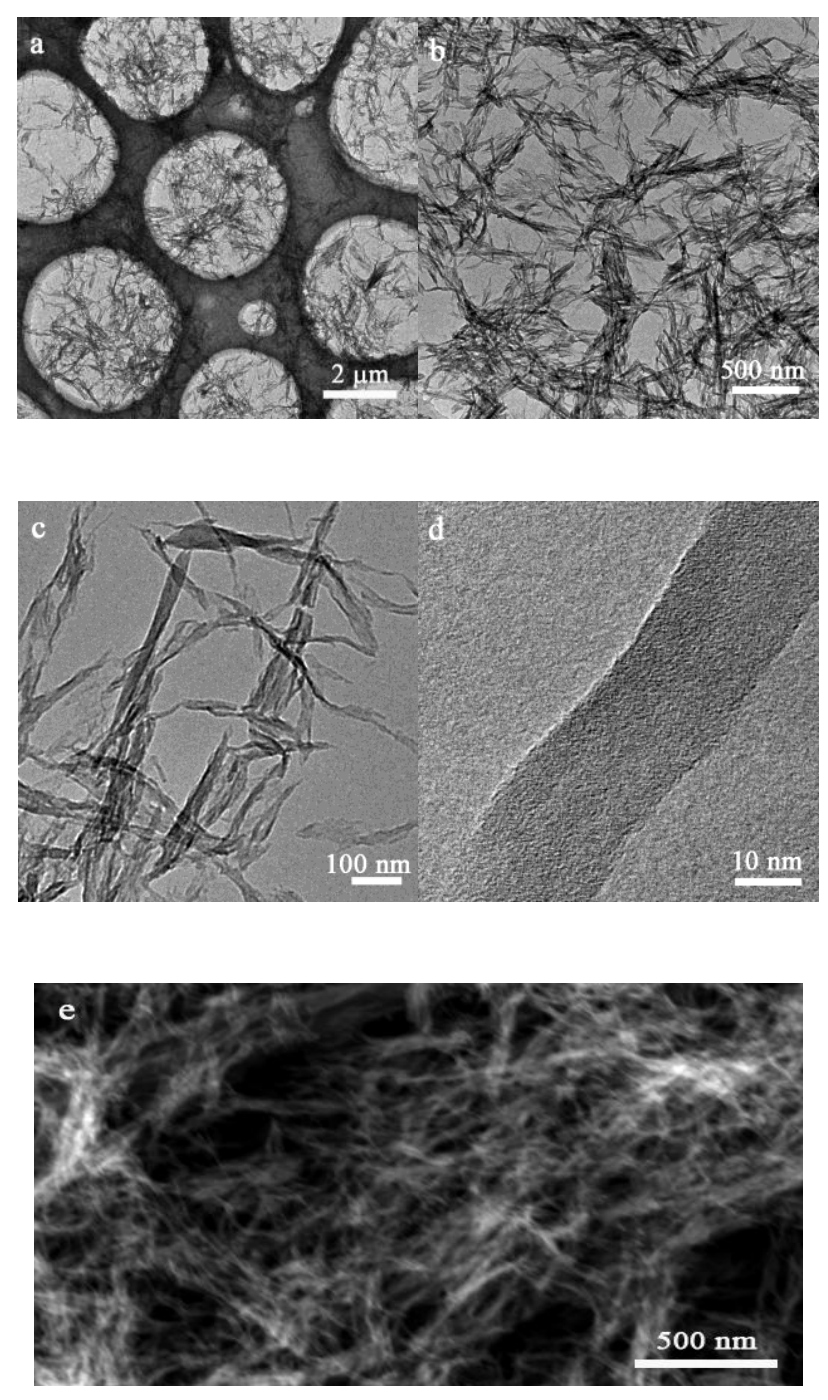

Fig. 1 (a-d) TEM images with different resolutions and (e) STEM image of the CNNSs.

Heating Melamine and the eutectic mixture of $\mathrm{NaCl} / \mathrm{KCl}$ in a covered crucible at $670{ }^{\circ} \mathrm{C}$ for an hour yielded yellow agglomerates. After removing excess amounts of salt and then freezing drying bright yellow powder (identified as CNNSs) was obtained. The elemental analysis determined that the atomic ratios of $\mathrm{C}$ to $\mathrm{N}$ in the bulk $\mathrm{CN}$ and CNNSs were 0.68 and 0.70 , respectively, both closer to carbon nitride networks such as melon (0.68 [53]) than to fully condensed $\mathrm{C}_{3} \mathrm{~N}_{4}(0.75)$. In addition, the elemental distribution of CNNSs was analyzed through elemental mapping images as shown in Figure S1. C and $\mathrm{N}$ are detectable and their composition 
is uniform throughout the samples, revealing the homogeneous distribution of the $\mathrm{C}$ and $\mathrm{N}$ in the CNNSs.

The morphology and thickness of the products was investigated in virtue of TEM, SEM and AFM. Compared to the bulk $\mathrm{CN}$ with a size of several micro-meters (Figure S2), the resulting polymeric carbon nitride present uniform seaweed shape, with widths of about $20 \mathrm{~nm}$ and lengths of several hundred nanometers (Fig. 1). The typical AFM image and thickness analyses (Fig. 2) reveal that the CNNSs are not smooth and the thickness is approximately $7 \mathrm{~nm}$.
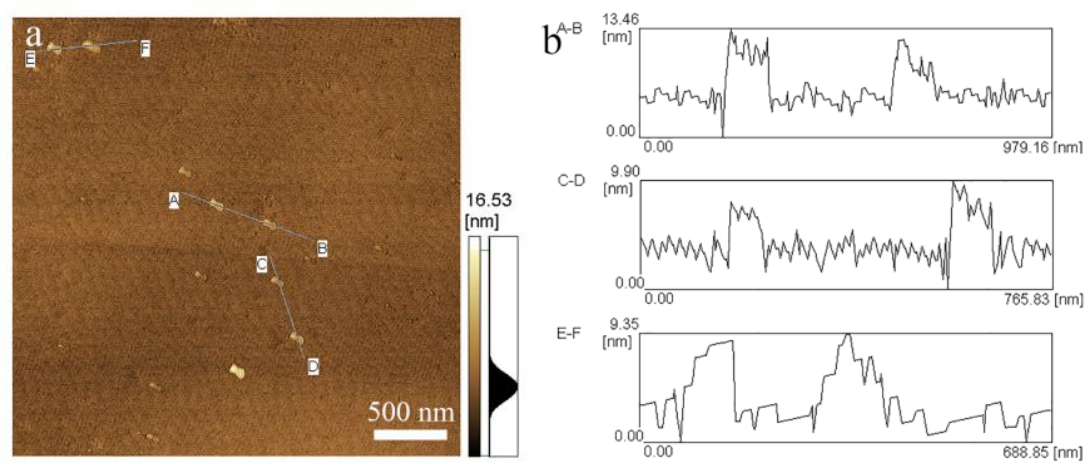

Fig. 2 (a) Typical AFM image of CNNSs and (b) the curves show the height of different CNNSs from the AFM images.

The representative XRD patterns and FTIR spectra of the CNNSs and bulk CN are displayed in Fig. 3a and $\mathrm{b}$. The bulk $\mathrm{CN}$ present two diffraction peaks at $27.8^{\circ}$ and $12.8^{\circ}$, attributed to the interplanar stacking of $\mathrm{CN}$ layers and in-plane repeating motif, respectively [34, 54, 55]. However, the CNNSs only show one peak $\left(27.8^{\circ}\right)$ and the low-angle reflection peak is absent, which may be caused by the decreased planar size of the CN layers. This is consistent with the observations from SEM and TEM images. In addition, no reflections are observed that can be assigned to the character of poly(triazine imid) (PTI) [42-44, 46, 47] and carbon nitride intercalation compound [49], suggesting that the higher melting point of $\mathrm{NaCl} / \mathrm{KCl}$ system hinder the interaction between salts and intermediates during the formation of carbon nitride. As 

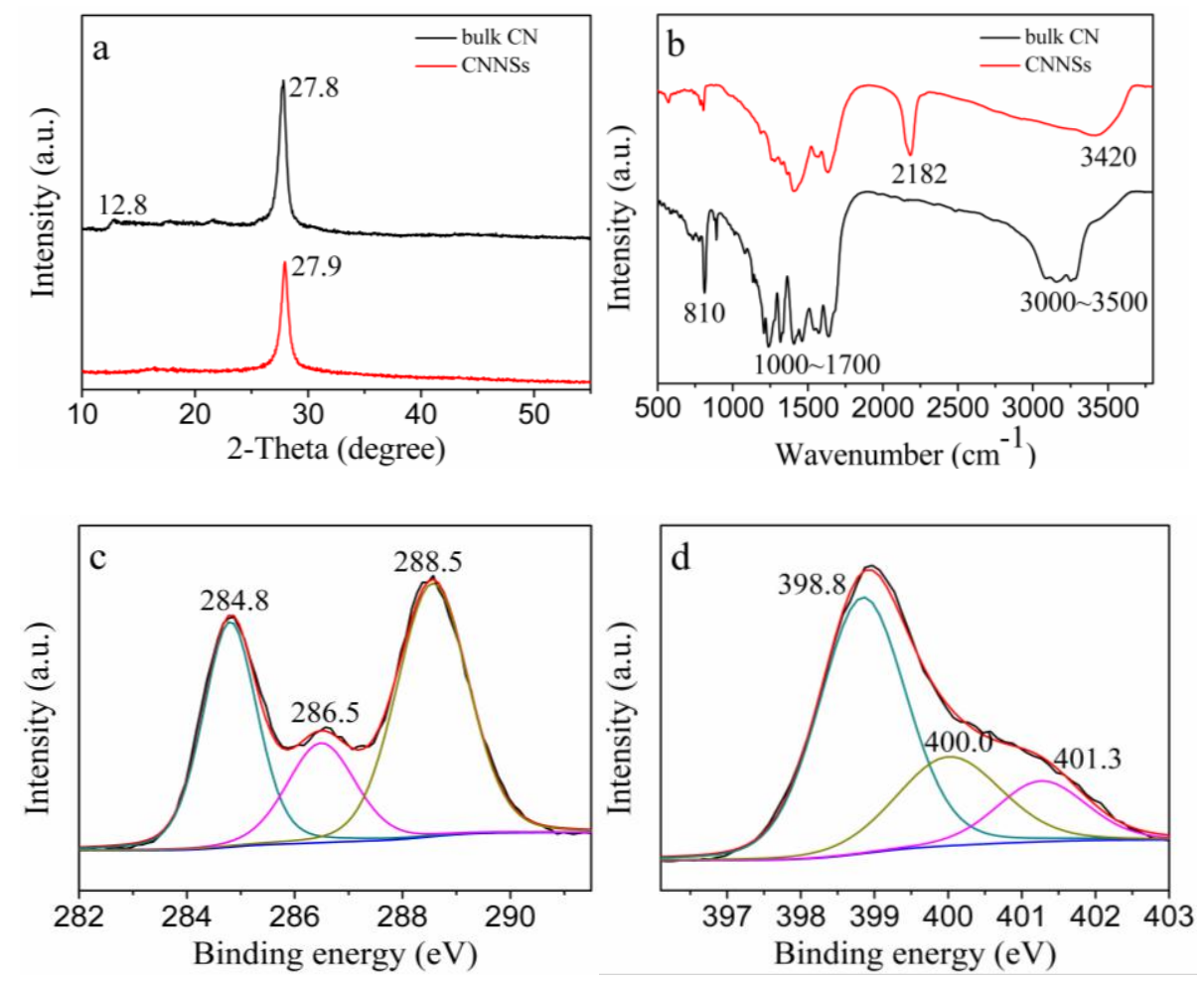

Fig. 3 (a) XRD patterns and (b) FTIR spectra of the bulk CN and CNNSs. (c) High resolution C 1s and (d) N 1s XPS spectra of the CNNSs.

displayed in Fig. 3b, in the case of the bulk $\mathrm{CN}$, the absorption band around $810 \mathrm{~cm}^{-1}$ stems from the ring-sextant out-of-plane bending vibration, the bands between 1200 and $1650 \mathrm{~cm}^{-1}$ correspond to stretching vibration of connected units of C-N(-C)-C (full condensation) or C-N-C (partial condensation), and the broad peaks between 3000 and $3300 \mathrm{~cm}^{-1}$ are indicative of N-H and /or $\mathrm{NH}_{2}$ stretching and hydrogen-bonding interactions. As compared to the bulk $\mathrm{CN}$, the FTIR spectrum of CNNSs exhibits two new bands at around 2182 and $3420 \mathrm{~cm}^{-1}$.The strong band at $2182 \mathrm{~cm}^{-1}$ corresponds to the stretch of cyano groups [55], which may stem from the decomposition of the tri-s-triazine units of $\mathrm{CNNSs}$ in the $\mathrm{NaCl} / \mathrm{KCl}$ molten salts and would be discussed below. The broad band at about $3420 \mathrm{~cm}^{-1}$ indicates the existence of some $\mathrm{NH}$ and $\mathrm{OH}$ groups in the sample [56]. A C=O stretching vibration peak at around $1623 \mathrm{~cm}^{-1}$ [57] locates in 
the same region to $\mathrm{C}=\mathrm{N}$ stretching, so it is difficult to specifically distinguish $\mathrm{C}=\mathrm{O}$ species in the CNNSs by FTIR spectra, confirmed by the results of the ${ }^{13} \mathrm{C}$ CP-MAS solid state NMR experiments. The presence of $\mathrm{C}=\mathrm{O}$ and $\mathrm{OH}$ groups can improve the dispersibility of CNNSs in water.

Insight into the chemical states and chemical composition in the CNNSs is provided by the results of the XPS. As shown in Fig. 3c, the C 1s spectra show three peaks. The peak located at $288.5 \mathrm{eV}$ originates from $\mathrm{sp}^{2} \mathrm{C}$ atoms bonded to $\mathrm{N}$ inside the triazine ring and $\mathrm{C}=\mathrm{O}$, and the other two peaks at 284.8 and $286.5 \mathrm{eV}$ are respond to the signal of standard reference carbon [34, $57,58]$ and the carbon in form of $\mathrm{C} \equiv \mathrm{N}[49,59]$, respectively. The binding energies of the $\mathrm{N} 1 \mathrm{~s}$ spectra are determined to be $398.8,400.0$ and $401.3 \mathrm{eV}$ (Fig. 3d). The major peak at $398.8 \mathrm{eV}$ is assigned to $\mathrm{sp}^{2}$-bonded $\mathrm{N}$ involved in the triazine rings. The two weak peaks at about 400.0 and $401.3 \mathrm{eV}$ originate from $\mathrm{N}$ atoms in the terminal $\mathrm{C} \equiv \mathrm{N}$ groups and bonded three carbon atoms in the aromatic, respectively $[49,58,59]$. The $\mathrm{O} 1 \mathrm{~s}$ peaks at 532.0 and $533.3 \mathrm{eV}$ shown in Figure $\mathrm{S} 3 \mathrm{a}$ are associated with oxygen in the states of $\mathrm{C}=\mathrm{O}$ and $\mathrm{C}-\mathrm{OH} / \mathrm{C}-\mathrm{O}-\mathrm{C}$, respectively $[58,60]$. It is worth noting that a weak $\mathrm{K} 2 \mathrm{~s}$ peak at $377.4 \mathrm{eV}$ is present (Figure S3c), which is well agreement with the reported binding energy of $\mathrm{K} 2 \mathrm{~s}$ for $\mathrm{KN}_{3}$. The results imply $\mathrm{K}^{+}$is coordinated into the big $\mathrm{C}-\mathrm{N}$ rings in the plane of CNNSs $[49,52]$. Besides, the $\mathrm{Na} 1 \mathrm{~s}$ peak appears at $1071.8 \mathrm{eV}$ (Figure S3d). The above results indicate there are slight ions in the CNNSs (Table S1), which may have an influence on the dispersibility of CNNSs in water [50].

To further identify the chemical structure of the products, ${ }^{13} \mathrm{C}$ and ${ }^{15} \mathrm{~N}$ CP-MAS solid state NMR experiments have been performed. The ${ }^{13} \mathrm{C}$ CP-MAS NMR spectra of CNNSs and bulk CN are displayed in Fig. 4. Two signal groups are found with peaks at about 164 and 156 ppm that correspond to $\mathrm{CN}_{2}\left(\mathrm{NH}_{\mathrm{x}}\right)$ and $\mathrm{CN}_{3}$ moieties, respectively, showing the existence of tri-s-triazine 
(s-heptazine) units in both the bulk CN and CNNSs [48, 53, 61-63]. As compared to the bulk CN, the ${ }^{13} \mathrm{C}$ CP-MAS NMR spectrum of CNNSs exhibits two new peaks at around 120 and $172 \mathrm{ppm}$. The former is characteristic of nitriles [64] and the latter may be assigned to carbonyl groups [65], corroborating the structure solution from the FTIR spectrum for the CNNS, which may stemmed from the decomposition of the tri-s-triazine units in the $\mathrm{NaCl} / \mathrm{KCl}$ molten salts and
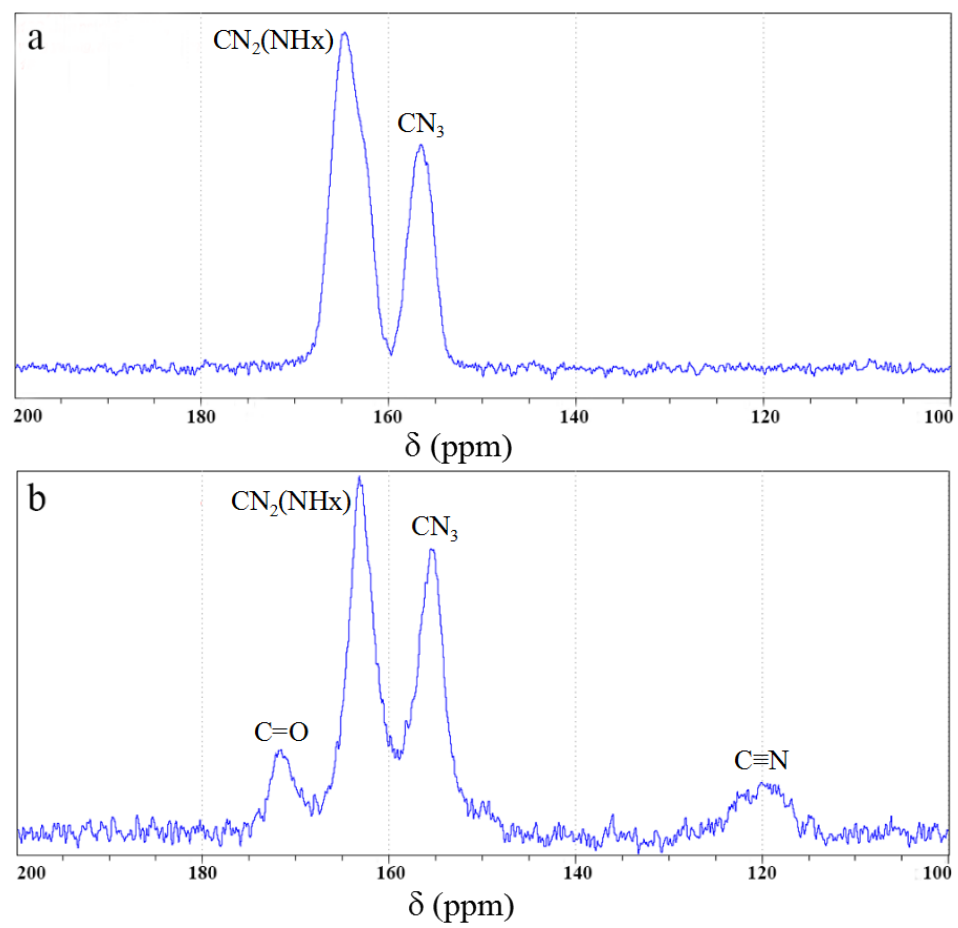

Fig. $4{ }^{13} \mathrm{C}$ CP-MAS NMR spectra of (a) the bulk CN and (b) CNNSs.

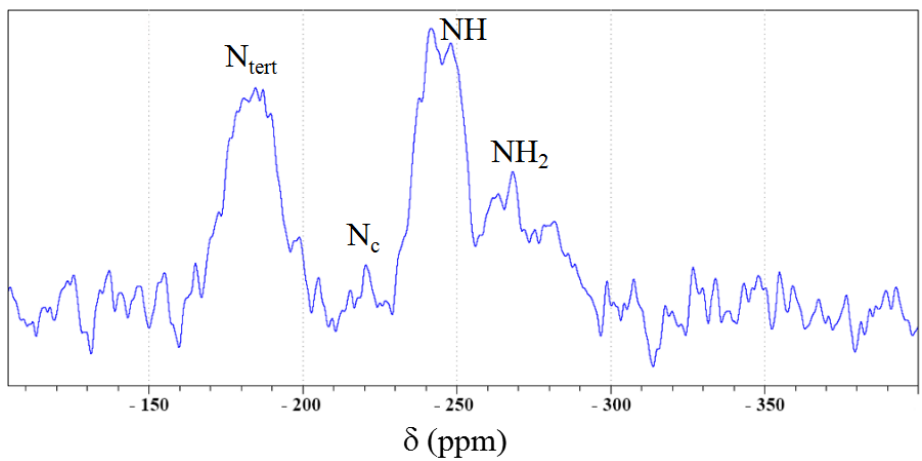

Fig. $5{ }^{15} \mathrm{~N}$ CP-MAS NMR spectrum of the CNNSs. 
would be discussed below. In addition, ${ }^{15} \mathrm{~N}$ solid-state NMR spectroscopy investigations are a helpful tool which can provide further information on the nature of the building blocks of condensed $\mathrm{CN}$ networks $[43,53]$. However, the ${ }^{15} \mathrm{~N}$ signal is very weak because the sensitivity of the ${ }^{15} \mathrm{~N}$ is much lower than ${ }^{1} \mathrm{H}$ nuclei $(1: 1000)$. Therefore, weak peaks are observed in the ${ }^{15} \mathrm{~N}$ CP-MAS solid-state NMR spectrum of CNNSs (Fig. 5) and the ${ }^{15} \mathrm{~N}$ cross-polarization with polarization inversion (CPPI) experiment becomes difficult. As outlined in Fig. 5, the weak isolated signal at $\delta=-220 \mathrm{ppm}$ is attributed to the central nitrogen atom ("Nc") in heptazine core, indicating the heptazine-based nature of CNNSs. The signals between $\delta=-180$ and $-198 \mathrm{ppm}$ are characteristic of tertiary (tert) nitrogen atoms. The signals between $\delta=-242$ and $-248 \mathrm{ppm}$ are assigned to $\mathrm{NH}$ groups, and the remaining signals at $\delta=-264,-268$ and $-281 \mathrm{ppm}$ belong to $\mathrm{NH}_{2}$ groups $[43,53,66]$, which suggest the formation of an only partially condensed C/N/H network. The signal of the $\mathrm{C} \equiv \mathrm{N}$ are probably covered by the broad of signals of the tert nitrogen atoms [67]. The results show the CNNSs are comprised of s-heptazine units $\left(\mathrm{C}_{6} \mathrm{~N}_{7}\right)$ yielding a partly condensed 1D network with cyano and carbonyl groups.

To explore the formation process of CNNSs, we monitored the structure change and morphology evolution of the products with temperature increasing. In the work of chu et al, microscale ribbon-like carbon nitride was observed growing directly from the surfaces of the $\mathrm{NaCl}$ crystal template [50]. Figure S4 gives the representative SEM images of the products collected at 600 and $650{ }^{\circ} \mathrm{C}$ without further treatment and no carbon nitride with special shape is found on the surface of $\mathrm{NaCl}$ or $\mathrm{KCl}$. Therefore, we proposed that the $\mathrm{NaCl} / \mathrm{KCl}$ mixture did not work as template in the formation of CNNSs. As shown in Figure S5, when melamine is heated to 400 ${ }^{\circ} \mathrm{C}$, the results of XRD indicate that the products are still melamine phase (JCPDS: 24-1645). Once the processing temperature are above $470{ }^{\circ} \mathrm{C}$, several new peaks form and the peaks are 
broadened, which indicates that the products have transformed from crystalline to amorphous. The products completely translate into polymeric carbon nitride at $600{ }^{\circ} \mathrm{C}$. The results of TGDSC thermograms demonstrate that the thermal polycondensation of melamine occurs at $470{ }^{\circ} \mathrm{C}$, which is lower than the melting temperature of mixing salts of $\mathrm{NaCl} / \mathrm{KCl}\left(663{ }^{\circ} \mathrm{C}\right)$ (Figure $\mathrm{S} 6$ and Table S2). This means polymeric carbon nitride has formed before increasing the temperature to the melting point of the mixing salts. As shown in Figure S7, the cyano groups appear above $600{ }^{\circ} \mathrm{C}$. Combining the results of XRD and FTIR analyses, we speculated the nitrile groups don't originate from the incomplete condensation of melamine, but stem from the cleavage of the tri-s-triazine units in polymeric carbon nitride, which finally prompt the macroscopic 3D polymeric carbon nitride to cleave into the 1D CNNSs. We directly treated the bulk $\mathrm{CN}$ powders in $\mathrm{NaCl} / \mathrm{KCl}$ molten salts and obtained the products with nitrile groups and nanoseaweeds shapes (Fig. 6), which further confirm our speculation. At the same time, some of the nitrile groups are prone to hydrolyze into carbonyl groups under high temperature and air. Considering the absence of nitrile groups in the bulk $\mathrm{CN}$, we proposed $\mathrm{NaCl} / \mathrm{KCl}$ molten slats play a role key in the formation of nitrile groups, namely, $\mathrm{NaCl} / \mathrm{KCl}$ salts can catalyze the cleavage of polymeric carbon nitride. TEM images of the $\mathrm{CN}(\mathrm{NaCl} / \mathrm{KCl}-600)$ (Figure S8) indicate $\mathrm{NaCl} / \mathrm{KCl}$ solid mixture do not effectively tailor the morphology of polymeric carbon nitride into nanoseaweeds. Only the temperature reaches $670^{\circ} \mathrm{C}$, the CNNSs are obtained in the $\mathrm{NaCl} / \mathrm{KCl}$ molten salts. Based on the above results, the possible formation process of CNNSs is proposed as follows. At the initial stage, the bulk $\mathrm{CN}$ was obtained by polycondensation of melamine molecules. Then, it was dispersed in the $\mathrm{NaCl} / \mathrm{KCl}$ molten salt when the temperature rose to $663{ }^{\circ} \mathrm{C}$. The molten-salt flux is a highly reactive medium, and the mobility of ions in these molten salts is very fast, which means the molten salts can easily intercalate into the 
inplanar and interplanar space of polymeric carbon nitride [49]. The intercalation gives rise to the cleavage of more and more tri-s-triazine units in polymeric carbon nitride followed by formation of cyano groups. Finally, macroscopic 3D polymeric carbon nitride was gradually disintegrated and converted into the 1D CNNSs.
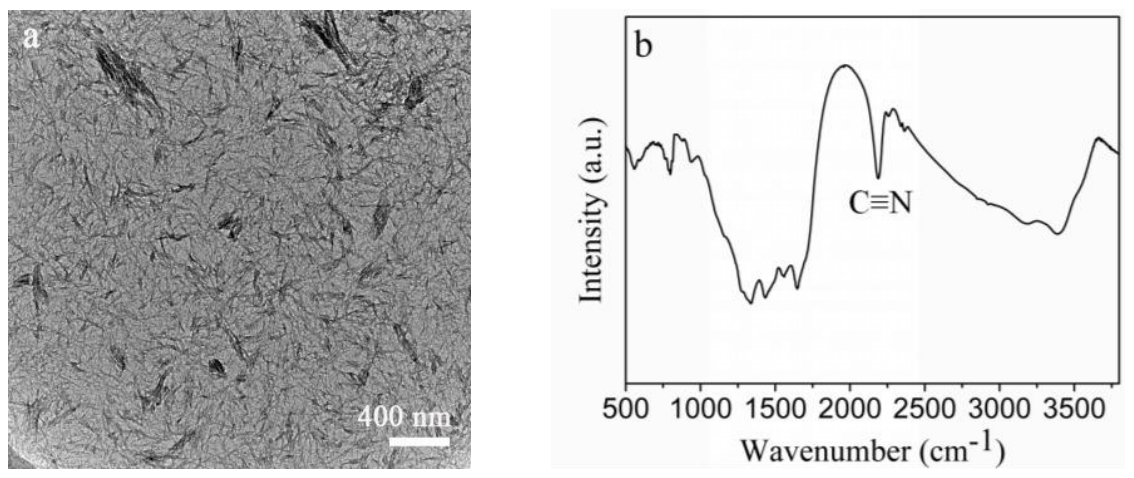

Fig. 6 (a)TEM images and (b) FTIR spectrum of the CNNSs from the bulk CN.

A possible synthetic strategy is illustrated in Scheme 1. Interestingly, the approach can also be used to prepare CNNSs using other precursors like dicyandiamide and guanlidine hydrochloride (Figure S9).

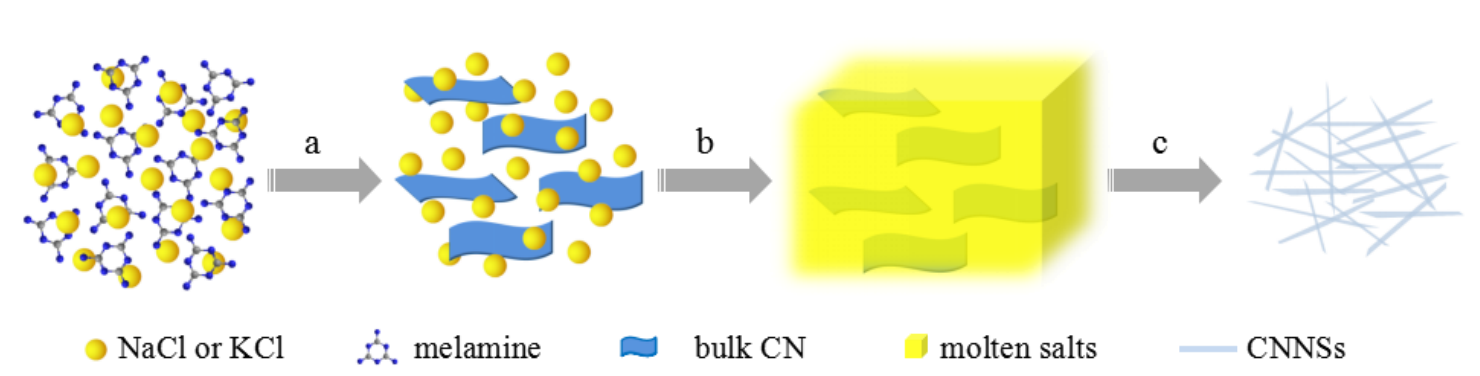

Scheme 1. Schematic illustration of the strategy for the preparation of CNNSs: (a) Formation of the bulk $\mathrm{CN}$ in $\mathrm{NaCl} / \mathrm{KCl}$ powder. (b) The bulk $\mathrm{CN}$ are impregnated with $\mathrm{NaCl} / \mathrm{KCl}$ molten salts. (c) The bulk $\mathrm{CN}$ are disintegrated and tailored into the $\mathrm{CNNSs}$ in $\mathrm{NaCl} / \mathrm{KCl}$ molten salts.

3.2 Water dispersibility of the CNNSs

Compared with the bulk $\mathrm{CN}$, the resulting CNNSs can well disperse in deionized water to form stable colloidal solution. To investigate the reason, a series of products were prepared by 
condensation of melamine in salt system at different temperature. Then, about $35 \mathrm{mg}$ of bulk CN (670), CN (600), CN (NaCl-600), CN (NaCl-600), CN (NaCl/KCl-600), CN (NaCl-670), CN (KCl-670), CNNSs (NaCl/KCl-670) were added into $8 \mathrm{~mL}$ of water, respectively. As given in Figure S10, after five days' standing, the bulk CN (670), CN (600), CN (NaCl-600), CN (NaCl$600)$ and $\mathrm{CN}(\mathrm{NaCl} / \mathrm{KCl}-600)$ are unstable in water and precipitation were found on the bottom of glass vials. In contrast, $\mathrm{CN}(\mathrm{NaCl}-670), \mathrm{CNNSs}(\mathrm{NaCl} / \mathrm{KCl}-670)$ and $\mathrm{CN}(\mathrm{KCl}-670)$ can well disperse in water to form a homogeneous suspension. We can see that the products can't disperse in water without slats. However, even if salts exist at $600^{\circ} \mathrm{C}$, the water dispersibility of the products are still poor. Only when the temperature reaches $670^{\circ} \mathrm{C}$, the products show good water dispersibility. It turns out that salt and temperature act synergistically in improving water dispersibility of the products. The detailed reasons are still under investigation.

To further examine the $\mathrm{pH}$ dependence of CNNSs aqueous solution, its aqueous solution with different $\mathrm{pH}$ values were prepared and the zeta potentials were measured. The solution of CNNSs ( $\mathrm{pH}=7$ ) displays well-defined Tyndall effect and is highly stable, showing no precipitation even after being stored for two months (Figure S11). Furthermore, the aqueous solution can be stable under weak acidic or alkaline environment with $\mathrm{pH}$ values ranging from 5 to 11 (Figure S12), during which the CNNSs are negatively charged with zeta potential of about $-30 \mathrm{mV}$ (Figure S13). This corresponds to strongly negative surface charges, which contributes to improve colloidal stability $[35,68]$.

\subsection{Optical Properties of CNNSs}

The optical properties of CNNSs is very different from the bulk CN. Under sunlight, the bulk $\mathrm{CN}$ is yellow while the CNNSs present bright yellow (Fig. 7a). Exposed to 365nm UV irradiation, the CNNSs can emit bright blue PL in both solid and colloidal states (Figure S11), while the bulk 
CN shows only weak yellow light. As given in Fig. 7b, the intrinsic absorption edge of CNNSs shows a slight blue shift and their band gap increases from 2.36 to $\sim 2.70 \mathrm{eV}$ with respect to the bulk CN. Meanwhile, the UV-vis spectrum of CNNSs extends to the whole visible light region and even to the infrared region, indicating in which the light absorbance of CNNSs enhances. The larger bandgap of CNNSs further confirmed by the blue shift of their emission spectrum by 20nm in Fig. 7c. The reason is attributed to the quantum confinement which can exert significant effect on the nanoscale carbon nitride and induce the large blue shift of band gap in the CNNSs $[69,70]$.

a
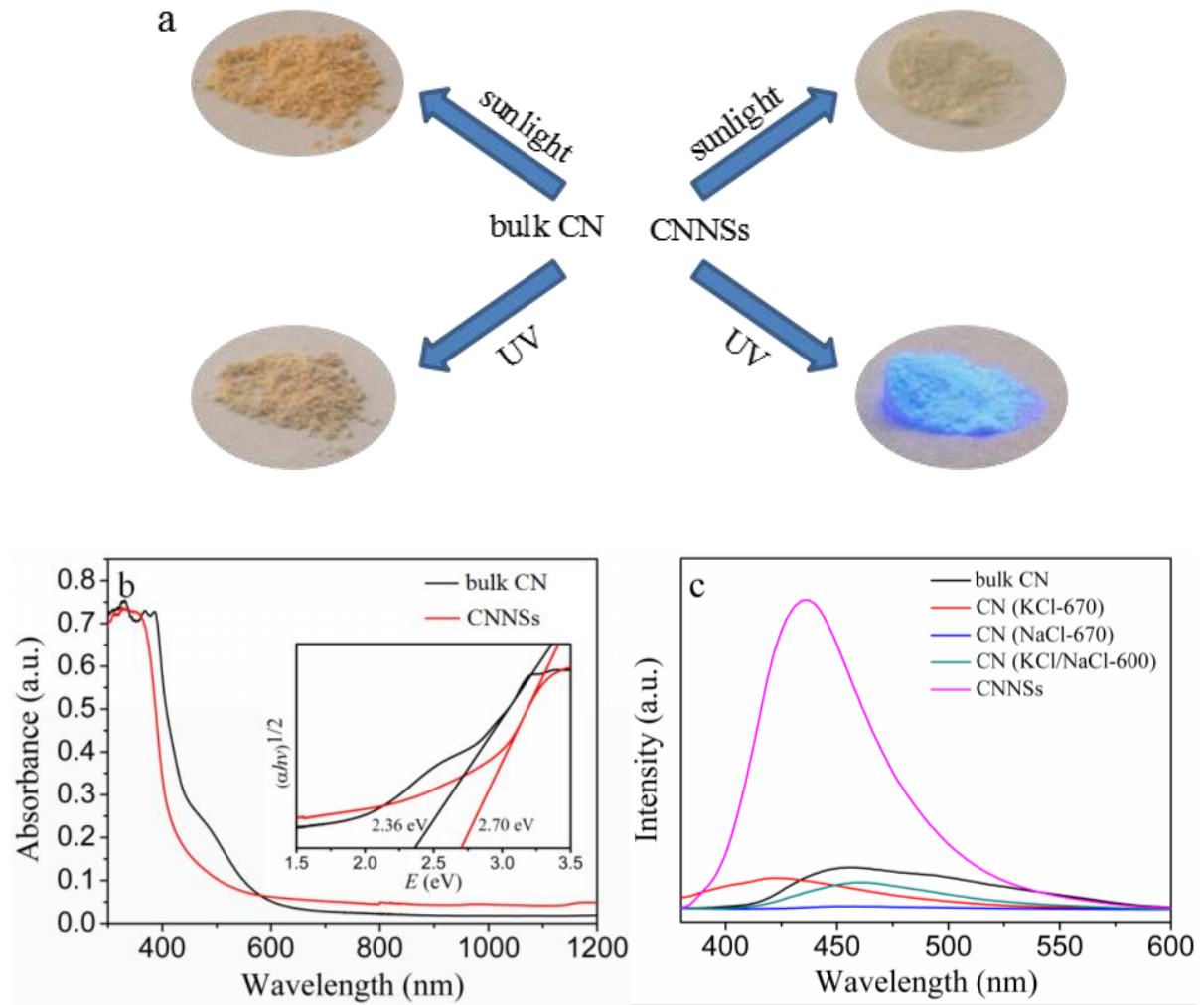

Fig. 7 (a) Optical images of the bulk CN and CNNSs under sunlight and $365 \mathrm{~nm}$ UV light, respectively. (b) UV-visible absorption spectra of the bulk CN and CNNSs. The inset in (b) is the Kubelka-Munk function plot providing the bandgaps. (c) PL spectra of the bulk CN, CNNSs and $\mathrm{CN}$. 
The CNNSs exhibit enhanced PL in contrast to the bulk CN. To elucidate the reason, we investigated the influence of various parameters, including the type of salts and treating temperature, on the PL results. Fig. 7c shows their PL spectra. It is found that CN (NaCl-670), $\mathrm{CN}(\mathrm{KCl}-670)$ and $\mathrm{CN}(\mathrm{NaCl} / \mathrm{KCl}-600)$ emit weaker PL in comparison with the bulk $\mathrm{CN}$, which is in good agreement with the phenomena reported in the literature [48, 49, 52]. This indicates the presence of metal ions that reduce the recombination rate of photo-generated charge carriers [49]. Contrary to the resulting CN products, the CNNSs exhibit enhanced PL. Xie et al. have demonstrated that reducing the macroscopic 3D materials into a microscopic 2D structure can promote photoresponse and improve PL property [34, 71, 72]. Therefore, the enhanced photoresponsivity of CNNSs could be attributed to their nanoscale size. The PL quantum yield of CNNSs measured using quinine sulfate as a reference is $3.8 \%$, comparable to that of the reported luminescent nanosized carbon nitride [36]. Interestingly, the CNNS solution shows bright blue PL under $365 \mathrm{~nm}$ UV light, and the PL intensity of CNNSs is very stable with no obvious photobleaching loss after irradiation with a Hg-lamp for even $9 \mathrm{~h}$ (Figure S14).

The PL mechanism of carbon nitride has received few coverage although it has been applied as luminesecent probes in biological field and chemosensing. Qiu et al proposed the PL of carbon nitride directly stem from $\mathrm{sp}^{2} \mathrm{C}=\mathrm{N}$ in conjugated tri-s-triazine rings [73]. Based the fact that the CNNSs retain the backbone of conjugated $\mathrm{C}=\mathrm{N}$ rings, the $\mathrm{PL}$ is induced by the transition between $\pi$ antibonding orbital of $\operatorname{sp}^{2} \mathrm{C}$ and lone pair orbital on $\mathrm{N}$ atoms, which is further supported by the reversible pH-dependent PL behavior of CNNSs (Fig. 8a). The CNNSs emit strong PL under basic conditions, and the PL intensity decreases with $\mathrm{pH}$ value decreasing. If $\mathrm{pH}$ is varied repeatedly from 1 to 14, the PL intensity switches reversibly (Fig. 8a). Under acidic conditions, nitrogen with potential base functionality (-C-N-) is protonated, forming a reversible 
interaction between the lone pair electronic and $\mathrm{H}^{+}$. Consequently, localization of the lone pair electronic enable the PL emission state inactive. However, under alkaline conditions, the lone pair electronic of $\mathrm{N}$ are restored and then the PL is recovered $[74,75]$. Fig. $8 \mathrm{~b}$ shows the PL spectra of CNNSs under different excitation wavelengths and the PL peaks have no significant shift with the excitation wavelength varying from 320 to $400 \mathrm{~nm}$, which could avoid autofluorescence during their applications [54].
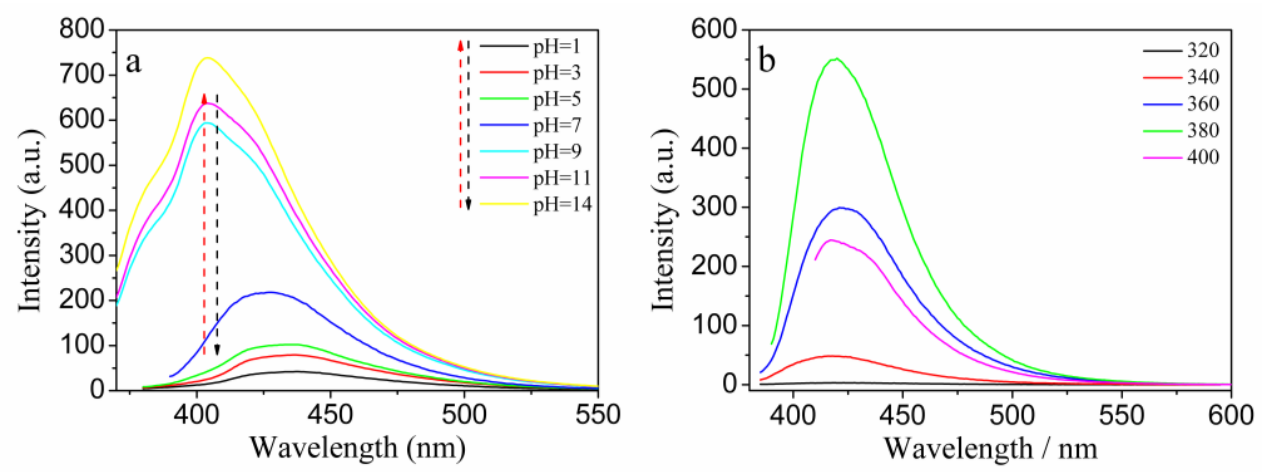

Fig. 8 (a) The dependence of the CNNS PL intensity on the solution pH. (b) PL spectra of the CNNS aqueous solution at different excitation wavelengths.

To study the photophysical behaviors of photoexcited charge carriers, the ns-level time-resolved fluorescence decay spectra of bulk CN and CNNSs were recorded (Fig. 9). Then, the radiative lifetimes with different percentages could be determined by fitting the decay spectra, as shown in Table 1. In detail, the short lifetime of $1.483 \mathrm{~ns}$ in the bulk $\mathrm{CN}$ increases up to $3.808 \mathrm{~ns}$ in the CNNSs, though its percentage decrease from $49.55 \%$ to $31.91 \%$. Both the long lifetime and percentage of charge carriers increase from $8.186 \mathrm{~ns}$ and $50.45 \%$ in the bulk to $11.76 \mathrm{~ns}$ and $68.09 \%$ in the nanoseaweeds. As a result, the weighted mean lifetime of $9.18 \mathrm{~ns}$ in the CNNSs are longer than that of $4.89 \mathrm{~ns}$ in the bulk $\mathrm{CN}$. It is believed that the increasing lifetimes of charge carriers may be relevant to the electron transport improvement and/or the changing electronic band structure, which arise from the quantum confinement in the CNNSs. 


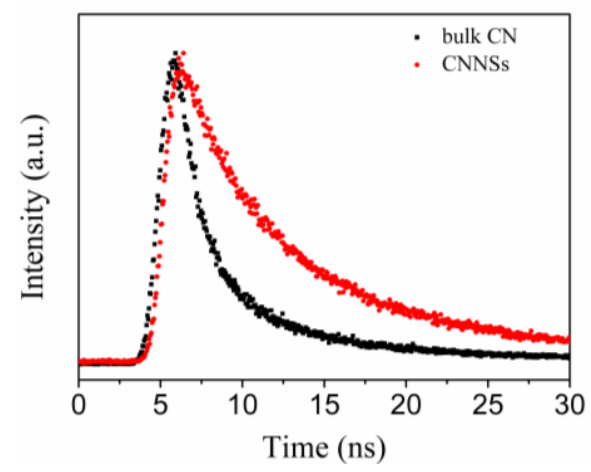

Fig. 9 Time-resolved fluorescence decay spectra of the bulk CN and CNNSs. The samples were excited by the incident light of $330 \mathrm{~nm}$ from a picosecond pulsed light-emitting diode.

Table 1. The fluorescence decay parameters in the bulk CN and CNNSs.

\begin{tabular}{lccccc}
\hline & $\tau_{1}(\mathrm{~ns})$ & Rel\% & $\tau_{2}(\mathrm{~ns})$ & Rel\% & $\tau_{\text {avg }}(\mathrm{ns})$ \\
\hline bulk CN & 1.483 & 49.55 & 8.186 & 50.45 & 4.89 \\
& & & & & \\
CNNSs & 3.808 & 31.91 & 11.76 & 68.09 & 9.18 \\
\hline
\end{tabular}

\subsection{Fluorescent Sensing of TC}

Due to good water dispersibility and strong PL, the potential application of CNNSs as luminescent probes to assay TC was explored.

A series of experiments were performed to optimize detection conditions. The influence of different buffers on the interaction between the CNNSs and TC has been investigated. Specifically, PBS buffer, Tris- $\mathrm{HCl}$ buffer, and citric acid buffer at $\mathrm{pH}=7.4$ were used during the detection procedures, respectively. As seen in Figure S15a, the $\left(F_{0} / F-1\right)$ value in PBS buffer is higher than that of other buffers, indicating that PBS buffer provides optimal performance for assaying TC. Therefore, the PBS buffer was applied to the following experiments. To study the effect of the CNNS concentration, experiments toward different concentration of CNNSs were 
carried out. As shown in Figure $\mathrm{S} 15 \mathrm{~b}$, the value of $\left(F_{0} / F-1\right)$ increases gradually with the concentration of CNNSs ranging from 0.06 to $0.12 \mathrm{mg} \mathrm{mL}^{-1}$, and begins to decrease when the concentrations are larger than $0.12 \mathrm{mg} \mathrm{mL}^{-1}$. Accordingly, $0.12 \mathrm{mg} \mathrm{mL}^{-1} \mathrm{CNNS}$ solution was selected throughout the experiments.
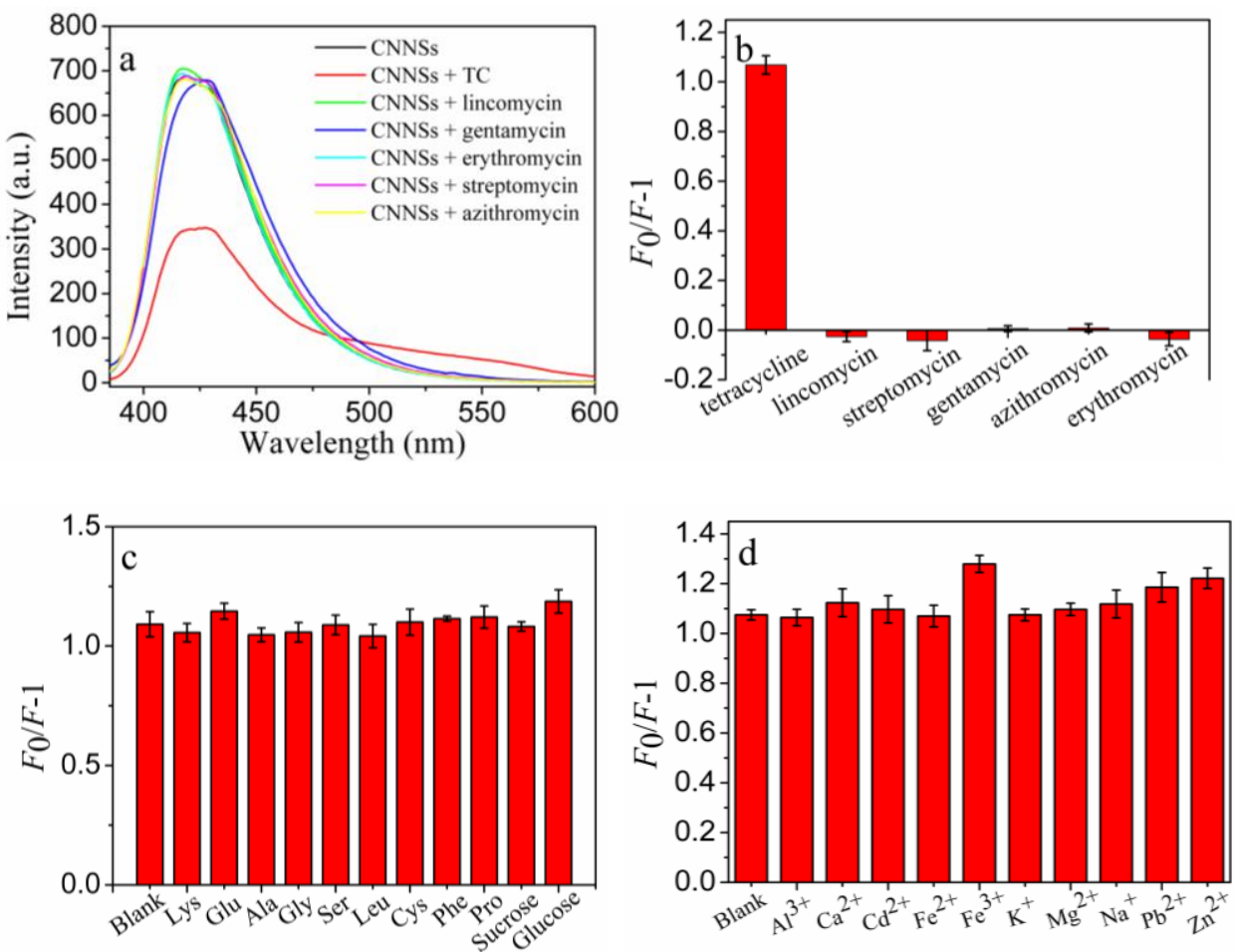

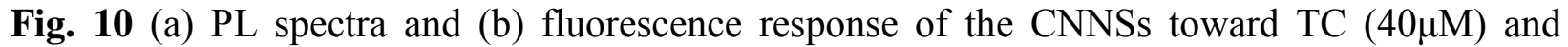
antibiotics $(80 \mu \mathrm{M})$. Fluorescence response of the CNNSs toward TC $(40 \mu \mathrm{M})$ in the presence of (c) saccharides $(80 \mu \mathrm{M})$, amino acid $(80 \mu \mathrm{M})$ and $(\mathrm{d})$ metal ions $(80 \mu \mathrm{M})$.

To assess the selectivity of CNNSs for TCs, fluorescence measurements were carried out in the presence of several antibiotics including lincomycin, streptomycin, gentamycin, azithromycin and erythromycin under the same conditions, and the results are displayed in Fig. 10a and b. It is seen that the introduction of TC into the CNNS solution causes an obvious decrease of PL intensity. In marked contrast, no obvious PL intensity changes could be observed by addition of other antibiotics into the CNNSs solution. To the best of our knowledge, there are usually 
coexisting common metal ions, saccharides, amino acids and so on in the TC preparations. To evaluate further specificity of the CNNSs, PL intensity changes of the CNNSs were examined in the presence of $\mathrm{TC}$ together with common metal ions $\left(\mathrm{Pb}^{2+}, \mathrm{Ca}^{2+}, \mathrm{Al}^{3+}, \mathrm{Mg}^{2+}, \mathrm{Zn}^{2+}, \mathrm{Na}^{+}, \mathrm{K}^{+}\right.$, $\mathrm{Cd}^{2+}, \mathrm{Fe}^{3+}, \mathrm{Fe}^{2+}$ ), saccharides (glucose, sucrose), and amino acids (Lys, Phe, Ser, Gly, Glu, Pro, Cys, Leu, Ala). In Fig. 10c and d, the "blank" refers to the mixture of CNNSs and TC, the other samples refer to the resulting solution by introducing the corresponding foreign coexisting substances into the blank. Compared to the intensity of the blank, the change of PL intensity are very small after introducing the foreign coexisting substances. Therefore, all the foreign coexisting substances have a negligible effect on the PL intensity. The results show that the CNNSs are highly selective toward TC.

To evaluate the CNNSs sensitivities against TC, the PL intensity of CNNSs mixed with various concentrations of TC was monitored. As given in Fig. 11a, the PL intensity of CNNSs decreases gradually with increasing TC concentration, indicating that TC can quench the PL of CNNSs. The quenching mechanism of fluorescence is analyzed by the UV-vis absorption spectra of CNNSs and TC. As given in Figure S16, no new peaks are observed when TC is added to the CNNSs, which proves no new substance is formed in the mixing system. The reasonable explanation for fluorescence quenching phenomenon is that TC may interact with the ground state of the groups on the surface of CNNSs and the photoinduced electrons of CNNSs are trapped by the surface-interaction TC $[57,76]$. The fitting curve in Fig. 11b (inset) shows linear relationship of $\left(F_{0} / F-1\right)$ versus the concentrations of TC over the range from 0 to $8 \mu \mathrm{M}$. The detection limits $(3 \sigma)$ for TC was $4 \times 10^{-8} \mathrm{M}$, which is comparable to other reported values [77, 78]. The results suggest that the CNNSs can serve as luminescent probes for determining TC. 

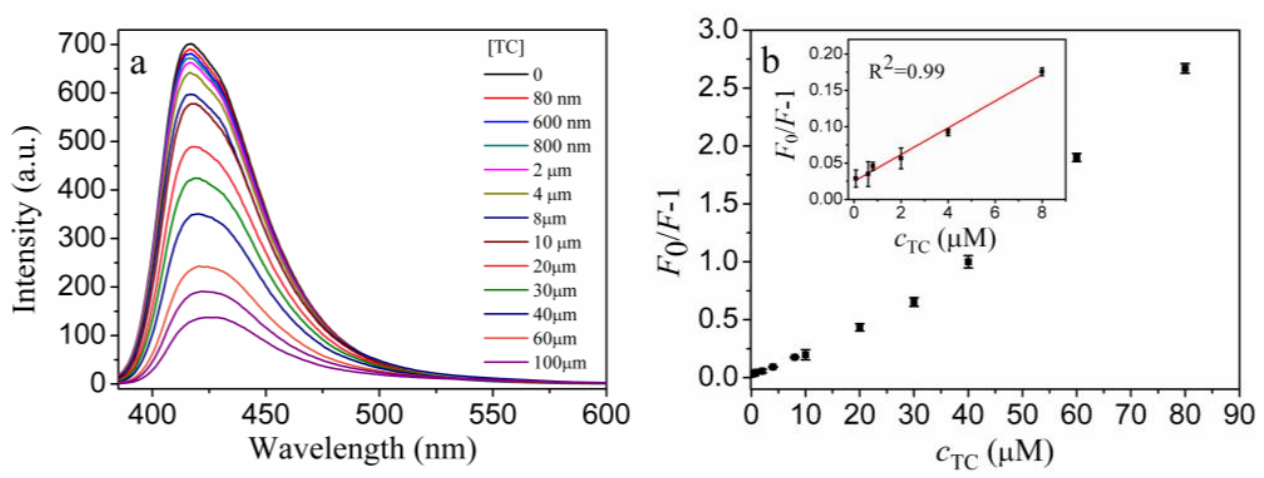

Fig. 11 (a) PL spectra of the CNNSs in the presence of different TC concentrations. (b)The dependence of $\left(\mathrm{F}_{0} / \mathrm{F}-1\right)$ on $\mathrm{TC}$ concentrations, and the inset is the linear relationship of $\left(\mathrm{F}_{0} / \mathrm{F}-1\right)$ versus TC concentrations.

\section{Conclusions}

In summary, we reported a facile, eco-friendly and one-step strategy to fabricate CNNSs from melamine in the $\mathrm{NaCl} / \mathrm{KCl}$ molten salts. The prepared CNNSs not only possess uniform shape and good water dispersibility, but also exhibit $\mathrm{pH}$-dependent photoluminescence behavior and stability under both basic and weak acidic conditions. Benefiting from the enhanced PL properties and high stability, the water-dispersible CNNSs can serve as green and effective luminescent probes for selective TC detection. In addition, the strategy provides a versatile approach to prepare water-dispersible luminescent CNNSs, which would be promising in both the preparation and extensive application of CNNSs.

\section{Acknowledgments}

We gratefully acknowledge the financial support of the National Science Foundation of China (NSFC) (21001096, 20971111, U1304204 and 21471133).

\section{REFERENCES}


[1] Wu P, Zhao T, Wang S, Hou X. Semicondutor quantum dots-based metal ion probes. Nanoscale 2013; 6(1):4364.

[2] Cheng L, Wang C, Liu Z. Upconversion nanoparticles and their composite nanostructures for biomedical imaging and cancer therapy. Nanoscale 2013; 5(1):23-37.

[3] Wang J, Ye D, Liang G, Chang J, Kong J, Chen J. One-step synthesis of water-dispersible silicon nanoparticles and their use in fluorescence lifetime imaging of living cells. J Mater Chem B 2014; 2(27):4338-45.

[4] Mu B, Zhang J, McNicholas TP, Reuel NF, Kruss S, Strano MS. Recent advances in molecular recognition based on nanoengineered platforms. Accounts Chem Res 2014; 47(4):979-88.

[5] Li L, Wu G, Yang G, Peng J, Zhao J, Zhu J. Focusing on luminescent graphene quantum dots: current status and future perspectives. Nanoscale 2013; 5(10):4015-39.

[6] Ding C, Zhu A, Tian Y. Functional surface engineering of C-Dots for fluorescent biosensing and in vivo bioimaging. Accounts Chem Res 2014; 47(1):20-30.

[7] Zhang L, Wang E. Metal nanoclusters: new fluorescent probes for sensors and bioimaging. Nano Today 2014; 9(1):132-57.

[8] Ruedas-Rama MJ, Walters JD, Orte A, Hall EAH. Fluorescent nanoparticles for intracellular sensing: A review. Anal Chim Acta 2012; 751:1-23.

[9] Wu C, Chiu DT. Highly fluorescent semiconducting polymer dots for biology and medicine. Angew Chem Int Ed 2013; 52(11):3086-109.

[10] Peng H, Chiu DT. Soft fluorescent nanomaterials for biological and biomedical imaging. Chem Soc Rev 2015; 44(14):4699-722.

[11] Hotzer B, Medintz IL, Hildebrandt N. Fluorescence in nanobiotechnology: sophisticated fluorophores for novel applications. Small 2012; 8(15):2297-326.

[12] Thomas A, Fischer A, Goettmann F, Antonietti M, Müller J, Schlögl R, et al. Graphitic carbon nitride materials: variation of structure and morphology and their use as metal-free catalysts. J Mater Chem 2008;18(41):4893-908.

[13] Zheng D, Huang C, Wang X. Post-annealing reinforced hollow carbon nitride nanospheres for hydrogen photosynthesis. Nanoscale 2015; 7(2):465-70.

[14] Zheng D, Pang C, Liu Y, Wang X. Shell-engineering of hollow $g-\mathrm{C}_{3} \mathrm{~N}_{4}$ nanospheres via copolymerization for photocatalytic hydrogen evolution. Chem Commun 2015; 51(47):9706-9. 
[15] Zhang G, Zhang M, Ye X, Qiu X, Lin S, Wang X. Iodine modified carbon nitride semiconductors as visible light photocatalysts for hydrogen evolution. Adv Mater 2014; 26(5):805-9.

[16] Fang J, Fan H, Li M, Long C. Nitrogen self-doped graphitic carbon nitride as efficient visible light photocatalyst for hydrogen evolution. J Mater Chem A 2015; 3(26):13819-26.

[17] Han Q, Hu C, Zhao F, Zhang Z, Chen N, Qu L. One-step preparation of iodine-doped graphitic carbon nitride nanosheets as efficient photocatalysts for visible light water splitting. J Mater Chem A 2015; 3(8):4612-9.

[18] Ong W, Tan L, Chai S, Yong S. Graphene oxide as a structure-directing agent for the two-dimensional interface engineering of sandwich-like graphene-g- $\mathrm{C}_{3} \mathrm{~N}_{4}$ hybrid nanostructures with enhanced visible-light photoreduction of $\mathrm{CO}_{2}$ to methane. Chem Commun 2015; 51(5):858-61.

[19] Ong W, Tan L, Chai S, Yong S. Heterojunction engineering of graphitic carbon nitride $\left(\mathrm{g}^{-} \mathrm{C}_{3} \mathrm{~N}_{4}\right)$ via Pt loading with improved daylight-induced photocatalytic reduction of carbon dioxide to methane. Dalton Trans. 2015; 44(3):1249-57.

[20] Ong W, Putri LK, Tan L, Chai S, Yong S. Heterostructured $\mathrm{AgX} / \mathrm{g}-\mathrm{C}_{3} \mathrm{~N}_{4}(\mathrm{X}=\mathrm{Cl}$ and $\mathrm{Br})$ nanocomposites via a sonication-assisted deposition-precipitation approach: Emerging role of halide ions in the synergistic photocatalytic reduction of carbon dioxide. Appl Catal B Environ 2016; 180:530-43.

[21] Qin J, Wang S, Ren H, Hou Y, Wang X. Photocatalytic reduction of $\mathrm{CO}_{2}$ by graphitic carbon nitride polymers derived from urea and barbituric acid. Appl Catal B Environ 2015; 179:1-8.

[22] Ong W, Tan L, Chai S, Yong S, Mohamed AR. Surface charge modification via protonation of graphitic carbon nitride $\left(\mathrm{g}-\mathrm{C}_{3} \mathrm{~N}_{4}\right)$ for electrostatic self-assembly construction of $2 \mathrm{D} / 2 \mathrm{D}$ reduced graphene oxide $(\mathrm{rGO}) / \mathrm{g}-\mathrm{C}_{3} \mathrm{~N}_{4}$ nanostructures toward enhanced photocatalytic reduction of carbon dioxide to methane. Nano Energy 2015; 13:75770.

[23] Li G, Nie X, Gao Y, An T. Can environmental pharmaceuticals be photocatalytically degraded and completely mineralized in water using $\mathrm{g}-\mathrm{C}_{3} \mathrm{~N}_{4} / \mathrm{TiO}_{2}$ under visible light irradiation?- Implications of persistent toxic intermediates. Appl Catal B Environ 2016; 180:726-32.

[24] Han C, Ge L, Chen C, Li Y, Xiao X, Zhang Y, et al. Novel visible light induced $\mathrm{Co}_{3} \mathrm{O}_{4}-\mathrm{g}-\mathrm{C}_{3} \mathrm{~N}_{4}$ heterojunction photocatalysts for efficient degradation of methyl orange. Appl Catal B Environ 2014; 147:546-53.

[25] Su F, Mathew SC, Möhlmann L, Antonietti M, Wang X, Blechert S. Aerobic oxidative coupling of amines by ccarbon nitride photocatalysis with visible light. Angew Chem Int Ed 2011; 50(3):657-60. 
[26] Chen Y, Zhang J, Zhang M, Wang X. Molecular and textural engineering of conjugated carbon nitride catalysts for selective oxidation of alcohols with visible light. Chem Sci 2013; 4(8):3244-8.

[27] Ma TY, Ran J, Dai S, Jaroniec M, Qiao SZ. Phosphorus-doped graphitic carbon nitrides grown In situ on carbon-fiber paper: flexible and reversible oxygen electrodes. Angew Chem Int Ed 2015; 54(15):4646-50.

[28] Jin J, Fu X, Liu Q, Zhang J. A highly active and stable electrocatalyst for the oxygen reduction reaction based on a graphene-supported g-C3N4@cobalt oxide core-shell hybrid in alkaline solution. J Mater Chem A 2013; 1(35):10538-45.

[29] Yang S, Feng X, Wang X, Müllen K. Graphene-based carbon nitride nanosheets as efficient metal-free electrocatalysts for oxygen reduction reactions. Angew Chem Int Ed 2011; 50(23):5339-43.

[30] Zhang Y, Bo X, Nsabimana A, Luhana C, Wang G, Wang H, et al. Fabrication of 2D ordered mesoporous carbon nitride and its use as electrochemical sensing platform for $\mathrm{H}_{2} \mathrm{O}_{2}$, nitrobenzene, and NADH detection. Biosens Bioelectron 2014;53:250-6.

[31] Wang D, Gu W, Zhang Y, Hu Y, Zhang T, Tao X, et al. Novel C-rich carbon nitride for room temperature $\mathrm{NO}_{2}$ gas sensors. RSC Adv 2014; 4(35):18003-6.

[32] Wu M, Wang Q, Sun Q, Jena P. Functionalized graphitic carbon nitride for efficient energy storage. J Phys Chem C 2013; 117(12):6055-9.

[33] Montigaud H, Tanguy B, Demazeau G, Alves I, Birot M, Dunogues J. Solvothermal synthesis of the graphitic form of C N as macroscopic sample 3 4. Diam Relat Mater 1999:1707-10.

[34] Zhang X, Xie X, Wang H, Zhang J, Pan B, Xie Y. Enhanced photoresponsive ultrathin graphitic-phase $\mathrm{C}_{3} \mathrm{~N}_{4}$ nanosheets for bioimaging. J Am Chem Soc 2013; 135(1):18-21.

[35] Schwinghammer K, Mesch MB, Duppel V, Ziegler C, Senker JR, Lotsch BV. Crystalline carbon nitride nanosheets for improved visible-light hydrogen evolution. J Am Chem Soc 2014; 136(5):1730-3.

[36] Chen L, Huang D, Ren S, Dong T, Chi Y, Chen G. Preparation of graphite-like carbon nitride nanoflake film with strong fluorescent and electrochemiluminescent activity. Nanoscale 2013; 5(1):225-30.

[37] Xu J, Zhang L, Shi R, Zhu Y. Chemical exfoliation of graphitic carbon nitride for efficient heterogeneous photocatalysis. J Mater Chem A 2013; 1(46):14766-72. 
[38] Sano T, Tsutsui S, Koike K, Hirakawa T, Teramoto Y, Negishi N, et al. Activation of graphitic carbon nitride $\left(\mathrm{g}-\mathrm{C}_{3} \mathrm{~N}_{4}\right)$ by alkaline hydrothermal treatment for photocatalytic NO oxidation in gas phase. J Mater Chem A 2013; 1(21):6489-96.

[39] Zhang X, Wang H, Wang H, Zhang Q, Xie J, Tian Y, et al. Single-layered graphitic- $\mathrm{C}_{3} \mathrm{~N}_{4}$ quantum dots for two-photon fluorescence imaging of cellular nucleus. Adv Mater 2014; 26(26):4438-43.

[40] Wang W, Yu JC, Shen Z, Chan DKL, Gu T. $g-\mathrm{C}_{3} \mathrm{~N}_{4}$ quantum dots: direct synthesis, upconversion properties and photocatalyticapplication. Chem Commun 2014; 50(70):10148-50.

[41] Liu X, Fechler N, Antonietti M. Salt melt synthesis of ceramics, semiconductors and carbon nanostructures. Chem Soc Rev 2013 ;42:8237-65.

[42] Michael J. Bojdys A, Jens-Oliver M Ller B, Markus Antonietti A, Thomas AA. Ionothermal synthesis of crystalline, condensed, graphitic carbon nitride. Chem Eur J 2008; 14(27):8177-82.

[43] Wirnhier E, D blinger M, Gunzelmann D, Senker JR, Lotsch BV, Schnick W. Poly(triazine imide) with intercalation of lithium and chloride ions $\left[\left(\mathrm{C}_{3} \mathrm{~N}_{3}\right)_{2}\left(\mathrm{NH}_{\mathrm{x}} \mathrm{Li} \mathrm{i}_{1-\mathrm{x}}\right)_{3} \cdot \mathrm{LiCl}\right]$ : a crystalline $2 \mathrm{D}$ carbon nitride network. Chem Eur J 2011; 17(11):3213-21.

[44] Chong SY, Jones JTA, Khimyak YZ, Cooper AI, Thomas A, Antonietti M, et al. Tuning of gallery heights in a crystalline 2D carbon nitride network. J Mater Chem A 2013; 1(4):1102-7.

[45] Fettkenhauer C, Weber J, Antonietti M, Dontsova D. Novel carbon nitride composites with improved visible light absorption synthesized in ZnCl. RSC Adv 2014; 4(77):40803-11.

[46] Yeilin Ham KMDC, Domen K. Synthesis and Photocatalytic Activity of Poly(triazine imide). Chem Asian J 2013; 8(1):218-24.

[47] Schwinghammer K, Tuffy B, Mesch MB, Wirnhier E, Martineau C, Taulelle F, et al. Triazine-based Carbon Nitrides for Visible-Light-Driven Hydrogen Evolution. Angew Chem Int Ed 2013; 52(9):2435-9.

[48] Dariya Dontsova SPMW, Guylhaine Clavel AMA. Triazoles: A new class of precursors for the synthesis of negatively charged carbon nitride derivatives. Chem Mater 2015; 27(15):5170-9.

[49] Gao H, Yan S, Wang J, Huang YA, Wang P, Li Z, et al. Towards efficient solar hydrogen production by intercalated carbon nitride photocatalyst. Phys Chem Chem Phys 2013; 15(41):18077-84.

[50] Yuan B, Chu Z, Li G, Jiang Z, Hu T, Wang Q, et al. Water-soluble ribbon-like graphitic carbon nitride $\left(\mathrm{g}-\mathrm{C}_{3} \mathrm{~N}_{4}\right)$ : green synthesis, self-assembly and unique optical properties. J Mater Chem C 2014; 2(39):8212-5. 
[51] Bojdys MJ, Severin N, Rabe JRP, Cooper AI, Thomas A, Antonietti M. Exfoliation of crystalline 2D carbon nitride: thin sheets, scrolls and bundles via mechanical and chemical routes. Macromol Rapid Comm 2013; 34(10):850-4.

[52] Zhao J, Ma L, Wang H, Zhao Y, Zhang J, Hu S. Novel band gap-tunable K-Na co-doped graphitic carbon nitride prepared by molten salt method. Appl Surf Sci 2015; 332:625-30.

[53] Lotsch BV, D blinger M, Sehnert J, Seyfarth L, Senker JR, Oeckler O, et al. Unmasking melon by a complementary approach employing electron diffraction, solid-state NMR spectroscopy, and theoretical calculations-structural characterization of a carbon nitride polymer. Chem Eur J 2007; 13(17):4969-80.

[54] Zhang S, Li J, Zeng M, Xu J, Wang X, Hu W. Polymer nanodots of graphitic carbon nitride as effective fluorescent probes for the detection of $\mathrm{Fe}^{3+}$ and $\mathrm{Cu}^{2+}$ ions. Nanoscale 2014; 6(8):4157-62.

[55] Yang S, Gong Y, Zhang J, Zhan L, Ma L, Fang Z, et al. Exfoliated graphitic carbon nitride nanosheets as efficient catalysts for hydrogen evolution under visible light. Adv Mater 2013; 25(17):2452-6.

[56] Bai X, Li J, Cao C. Synthesis of hollow carbon nitride microspheres by an electrodeposition method. Appl Surf Sci 2010; 256(8):2327-31.

[57] Yang X, Luo Y, Zhu S, Feng Y, Zhuo Y, Dou Y. One-pot synthesis of high fluorescent carbon nanoparticles and their applications as probes for detection of tetracyclines. Biosens Bioelectron 2014; 56:6-11.

[58] Gao D, Xu Q, Zhang J, Yang Z, Si M, Yan Z, et al. Defect-related ferromagnetism in ultrathin metal-free g- $\mathrm{C}_{3} \mathrm{~N}_{4}$ nanosheets. Nanoscale 2014; 6(5):2577-81.

[59] Li C, Yang X, Yang B, Yan Y, Qian Y. Synthesis and characterization of nitrogen-rich graphitic carbon nitride. Mater Chem Phys 2007; 103(2-3):427-32.

[60] Yang Z, Xu M, Liu Y, He F, Gao F, Su Y, et al. Nitrogen-doped, carbon-rich, highly photoluminescent carbon dots from ammonium citrate. Nanoscale 2014; 6(3):1890-5.

[61] Jürgens B, Irran E, Senker J, Kroll P, Müller H, Schnick W. Melem (2,5,8-Triamino-tri-s-triazine), an important intermediate during condensation of melamine rings to graphitic carbon nitride: synthesis, structure determination by X-ray Powder Diffractometry, solid-state NMR, and theoretical studies. J Am Chem Soc 2003; 125(34):10288300.

[62] Holst JR, Gillan EG. From Triazines to Heptazines: Deciphering the local structure of amorphous nitrogen-rich carbon nitride materials. J Am Chem Soc 2008; 130(23):7373-9. 
[63] Kailasam K, Epping JD, Thomas A, Losse S, Junge H. Mesoporous carbon nitride-silica composites by a combined sol-gel/thermal condensation approach and their application as photocatalysts. Energy Environ Sci 2011; 4(11):4668-74.

[64] Horvath-Bordon E, Kroke E, Svoboda I, Fuess H, Riedel R. Potassium melonate, $\mathrm{K}_{3}\left[\mathrm{C}_{6} \mathrm{~N}_{7}(\mathrm{NCN})_{3}\right] \cdot 5 \mathrm{H}_{2} \mathrm{O}$, and its potential use for the synthesis of graphite-like $\mathrm{C}_{3} \mathrm{~N}_{4}$ materials. New J Chem 2005; 29(5):693-9.

[65] Schwarzer A, Böhme U, Kroke E. Use of melem as a nucleophilic reagent to form the triphthalimide $\mathrm{C}_{6} \mathrm{~N}_{7}$ (phthal) ${ }_{3}$-New Targets and Prospects. Chem Eur J 2012; 18(38):12052-8.

[66] Wirnhier E, Mesch MB, Senker J, Schnick W. Formation and characterization of melam, melam hydrate, and a melam-melem adduct. Chem Eur J 2013; 19(6):2041-9.

[67] He C, Lin G, Upton KT, Imanaka H, Smith MA. Structural investigation of titan tholins by solution-state ${ }^{1} \mathrm{H}$, ${ }^{13} \mathrm{C}$, and ${ }^{15} \mathrm{~N}$ NMR: one-dimensional and decoupling experiments. J Phys Chem A 2012; 116(19):4760-7.

[68] Lei W, Portehault D, Dimova R, Antonietti M. Boron carbon nitride nanostructures from salt melts: tunable water-soluble phosphors. J Am Chem Soc 2011; 133(18):7121-7.

[69] Dong F, Wang Z, Li Y, Ho W, Lee SC. Immobilization of polymeric $\mathrm{g}_{-} \mathrm{C}_{3} \mathrm{~N}_{4}$ on structured ceramic foam for efficient visible light photocatalytic air purification with real indoor illumination. Environ Sci Technol 2014; 48(17):10345-53.

[70] Dong F, Ou M, Jiang Y, Guo S, Wu Z. Efficient and durable visible light photocatalytic performance of porous carbon nitride nanosheets for air purification. Ind Eng Chem Res 2014; 53(6):2318-30.

[71] Sun Y, Cheng H, Gao S, Sun Z, Liu Q, Liu Q, et al. Freestanding tin disulfide single-layers realizing efficient visible-light water splitting. Angew Chem Int Ed. 2012; 51(35):8727-31.

[72] Xu TG, Zhang C, Shao X, Wu K, Zhu YF. Monomolecular-layer $\mathrm{Ba}_{5} \mathrm{Ta}_{4} \mathrm{O}_{15}$ nanosheets: synthesis and investigation of photocatalytic properties. Adv Funct Mater. 2006; 16(12):1599-607.

[73] Zhang Y, Pan Q, Chai G, Liang M, Dong G, Zhang Q, et al. Synthesis and luminescence mechanism of multicolor-emitting g-C3N4 nanopowders by low temperature thermal condensation of melamine. Sci Rep 2013; $3: 1-8$

[74] Pan D, Zhang J, Li Z, Wu M. Hydrothermal route for cutting graphene sheets into blue-luminescent graphene quantum dots. Adv Mater 2010; 22(6):734-8. 
[75] Zhou Z, Shen Y, Li Y, Liu A, Liu S, Zhang Y. Chemical cleavage of layered carbon nitride with enhanced photoluminescent performances and photoconduction. ACS Nano 2015; 9(12):12480-7.

[76] Tian J, Liu Q, Asiri AM, Al-Youbi AO, Sun X. Ultrathin graphitic carbon nitride nanosheet: a highly efficient fluorosensor for rapid, ultrasensitive detection of $\mathrm{Cu}^{2+}$. Anal Chem 2013; 85(11):5595-9.

[77] Hou J, Yan J, Zhao Q, Li Y, Ding H, Ding L. A novel one-pot route for large-scale preparation of highly photoluminescent carbon quantum dots powders. Nanoscale 2013; 5(20):9558-61.

[78] Zong J, Yang X, Trinchi A, Hardin S, Cole I, Zhu Y, et al. Carbon dots as fluorescent probes for "off-on" detection of $\mathrm{Cu}^{2+}$ and 1-cysteine in aqueous solution. Biosens Bioelectron. 2014; 51:330-5. 